\title{
Two novel endoscopic esophageal lengthening and reconstruction techniques
}

\author{
Silvana Perretta $\cdot$ James K. Wall . \\ Bernard Dallemagne • Michael Harrison • \\ François Becmeur $\cdot$ Jacques Marescaux
}

Received: 4 January 2011/Accepted: 28 February 2011/Published online: 10 May 2011

(C) Springer Science+Business Media, LLC 2011

\begin{abstract}
Background Esophageal reconstruction presents a significant clinical challenge in patients ranging from neonates with long-gap esophageal atresia to adults after esophageal resection. Both gastric and colonic replacement conduits carry significant morbidity. As emerging organsparring techniques become established for early stage esophageal tumors, less morbid reconstruction techniques are warranted. We present two novel endoscopic approaches for esophageal lengthening and reconstruction in a porcine model.

Methods Two models of esophageal defects were created in pigs (30-35 kg) under general anesthesia and subsequently reconstructed with the novel techniques. The first model was a segmental defect of the esophagus created by thoracoscopically transecting the esophagus above the gastroesophageal (GE) junction. The first reconstruction technique involved bilateral submucosal endoscopic lengthening myotomies (BSELM) with a magnetic compression anastomosis (MAGNAMOSIS ${ }^{\mathrm{TM}}$ ). The second
\end{abstract}

Electronic supplementary material The online version of this article (doi:10.1007/s00464-011-1711-4) contains supplementary material, which is available to authorized users.

S. Perretta $(\bowtie) \cdot$ J. K. Wall · B. Dallemagne $\cdot$ J. Marescaux Institute de Recherche contra les Cancers de l'Appareil Digestif (IRCAD), 1 Place de l'Hopital, 67091 Strasbourg Cedex, France e-mail: silvana.perretta@ircad.fr

\section{Harrison}

Department of Surgery, University of California San Francisco, San Francisco, CA, USA

\section{F. Becmeur}

Department of Pediatric Surgery, University Hospital

of Strasbourg, Strasbourg, France model was a wedge defect in the anterior esophagus created above the GE junction through a laparotomy. The second reconstruction technique involved an inverted mucosal-submucosal sleeve transposition graft (IMSTG) that crossed the esophageal gap and was secured in place with a self-expandable covered esophageal stent.

Results Both techniques were feasible in the pig model. The BSELM approach lengthened the esophagus $1 \mathrm{~cm}$ for every $2 \mathrm{~cm}$ length of myotomy. The myotomy targeted only the inner circular fibers of the esophagus, with preservation of the longitudinal layer to protect against long-term dilation and pouching. The IMSTG approach generated a vascularized mucosal graft almost as long as the esophagus itself.

Conclusions Emerging endoscopic capabilities are enabling complex endoluminal esophageal procedures. BSELM and IMSTG are two novel and technically feasible approaches to esophageal lengthening and reconstruction. Further survival studies are needed to establish the safety and efficacy of these techniques.

Keywords Esophagus - NOTES · Myotomy ·

Endoscopy $\cdot$ Cancer $\cdot$ Atresia

Disclosure Drs. S. Perretta, J. K. Wall, B. Dallemagne, M. Harrison, F. Becmeur, and J. Marescaux have no conflicts of interest or financial ties to disclose. 